Allowing, as seems reasonable from our data, a minimum of three years for the recanalisation to become apparent, this gives an incidence of one in 2300. Other possible estimates of incidence are given in table II. All must, however, be considered to be minimal estimates because, firstly, motile sperm may return to the ejaculate without the man seeking medical advice because no pregnancy follows; secondly, some pregnancies may not be reported to the operating surgeon or centre; and, thirdly-and most relevantly as two zero sperm counts after vasectomy have been widely believed to confirm permanent sterility-once a woman becomes pregnant there is reluctance to perform a sperm count in her partner for fear of precipitating marital breakdown.

Only Esho et al have reported an attempt to collect annual specimens of semen. ${ }^{9}$ Only 215 out of 1000 men who had undergone vasectomy complied, in three of whom recanalisation was found to have occurred. These limited data suggest that late restoration of fertility could occur in as many as $1 \%$ of patients. The rarity, however, of reported conceptions occurring after vasectomy brings such a high incidence into question. A reevaluation of this work is required, and, pending more data, our preferred estimate would be roughly one in 2000 .

The important practical conclusions from this information are that, firstly, the rare possibility of late failure of vasectomy should be taken into account during preoperative counselling and in the wording of letters confirming the achievement of sterility (though it should be emphasised that abstinence remains the only method of birth control that is more effective than vasectomy judged to be successful by two zero sperm counts); and, secondly, if the partner of a man who has undergone vasectomy becomes pregnant a semen analysis should be performed before it is assumed that the fertile sperm came from another source.

We thank Mr J K Monro, Dr T Black, and Dr P Mortimer for permission to report on their patients; the surgeons, nurses, and administrative staff of this clinic, notably Sisters Ashwin and Turner; and Ms A Kilcooley and Mrs J Ford for secretarial help.

\section{References}

' Barnes MN, Blandy JP, England HR, et al. One thousand vasectomies. Br Med $f$ 1973; iv:216-21.

Rees RWH. Vasectomy: problems of follow up. Proc $R$ Soc Med 1973;66:52-4.

3 Blandy JP. Vasectomy. Br F Hosp Med 1979;21:520-7. Bunge RG. Bilateral spontaneous reanastomosis of the ductus deferens. F Urol
1968;100:762.

'Pugh RCB, Hanley HG. Spontaneous recanalisation of the divided vas deferens. Br F Urol 1969;41:340-7.

Livingstone ES. Vasectomy: a review of 3200 operations. Can Med Assoc $\mathcal{F}$ 1971; 105: 1065

Franzblau AH. Spontaneous reanastomosis of the vas deferens. Rocky Mountain Medical fournal 1973;70:35-6.

Esho JO, Ireland

Jina RP, Jain DP, Nagar AM, Gup
deferens. Int Surg 1977;62:557-8.

Spencer CW. Vasectomies in a health centre. Novum 1981;16 (August):4-5.

12 Hayashi $\mathrm{H}$, Cedenho AP, Sadi A. The mechanism of spontaneous recanalisation of human vasectomised ductus deferens. Fertil Steril 1983;40:269-70.

${ }^{3}$ Schmidt SS, Morris RR. Spermatic granuloma; the complication of vasectomy. Fertil Steril 1973,24:941-7.

(Accepted 27 April 1984)

\title{
Blood thiamine and thiamine phosphate ester concentrations in alcoholic and non-alcoholic liver diseases
}

\author{
M DANCY， G EVANS, M K GAITONDE, J D MAXWELL
}

\begin{abstract}
Thiamine state was investigated in patients with alcoholic liver disease, patients with various non-alcoholic liver diseases, and controls using a direct technique (thiochrome assay) to measure thiamine, thiamine monophospate, and the active coenzyme thiamine pyrophosphate in whole blood after isolating the fractions by ion exchange chromatography. Overall nutrition was similar in all groups as assessed by anthropometry, and no patient had clinical evidence of thiamine deficiency.

There was no significant difference among the groups in mean concentration of any form of thiamine. The scatter was much greater in patients with alcoholic liver disease but only $8.7 \%$ had biochemical thiamine deficiency (defined as a blood concentration of the active coenzyme greater than 2 SD below the mean
\end{abstract}

Departments of Medicine and Biochemistry, St George's Hospital and Medical School, London

M DANCY, MA, MRCP, senior registrar in medicine

G EVANS, BSC, research assistant

$M$ K GAITONDE, MSC, PHD, senior scientist

J D MAXWELL, MD, FRCP, senior lecturer in medicine

Correspondence and requests for reprints to: Dr J D Maxwell, Department of Medicine II, St George's Hospital Medical School, London SW17 0RE. control value). An unexpected finding was of abnormally high total thiamine concentrations ( $>2$ SD above the mean control value) in $17 \cdot 4 \%$ of patients with alcoholic liver disease, the highest concentrations being found in two patients with severe alcoholic hepatitis and cirrhosis. The ratio of phosphorylated to unphosphorylated thiamine was calculated as an index of phosphorylation and, although the mean did not differ significantly among the groups, the range was greatest in alcoholic liver disease. The lowest ratios occurred in the two patients with severe alcoholic hepatitis, but neither had evidence of thiamine pyrophosphate deficiency.

Contrary to studies using indirect assay techniques, these results suggest that thiamine deficiency is unusual in well nourished patients with alcoholic liver disease. The new finding of unexpectedly high thiamine concentrations in some patients may be due to abnormalities of hepatic storage or release in liver disease, particularly in severe alcoholic hepatitis. There was no convincing evidence of impaired thiamine phosphorylation in any patients with liver disease. Conclusions from studies using indirect assays on the prevalence and mechanisms of thiamine deficiency in liver diseases may not be valid.

\section{Introduction}

In affluent countries overt thiamine deficiency resulting in clinical syndromes such as Wernicke's encephalopathy, peripheral neuropathy, or beriberi heart disease is most often a 
consequence of chronic alcoholism. Gross deficiency states, however, are unusual in alcoholics in Britain and the United States, who may be as well nourished as non-alcoholic subjects of a similar social class. ${ }^{1}$

Thiamine is phosphorylated in the presence of pyrophosphokinase and adenosine triphosphate to thiamine pyrophosphate, which functions as a coenzyme for transketolase in the utilisation of pentose phosphate via the hexose monophosphate shunt. Figure 1 shows how the phosphate esters of thiamine are related metabolically. ${ }^{2}$

Estimates of the prevalence of subclinical thiamine deficiency in alcoholics have ranged from $30 \%$ to $80 \%{ }^{3}$. Thiamine state in those studies, however, was assessed indirectly, usually by measuring transketolase activity in vitro, with or without the effect of added thiamine pyrophosphate. Evidence suggests that indirect assays correlate poorly with direct measurement of thiamine ${ }^{45}$ and that measurement of thiamine pyrophosphate may be a more sensitive indicator of thiamine deficiency. ${ }^{6}$ Moreover, in alcoholism the direct effect of alcohol and acetaldehyde on transketolase ${ }^{7}$ must be taken into account. We therefore report the direct measurement of the concentrations in blood of unphosphorylated thiamine and thiamine phosphate esters (monophosphate and pyrophosphate) in patients with alcoholic and non-alcoholic liver diseases.

\section{Patients and methods}

Blood thiamine and thiamine phosphate ester concentrations were measured in three groups of patients, none of whom had been taking thiamine before the study. Thiamine triphosphate was not detected in measurable amounts. No patient had malignant disease.

Patients with alcoholic liver disease-Twenty three patients were diagnosed as having alcoholic liver disease on the basis of prolonged excessive alcohol consumption and abnormal liver function. Liver biopsy appearances were compatible with the diagnosis in the 15 who submitted to needle biopsy, of whom five had established cirrhosis. Five claimed to have been abstinent for at least one month at the time of study.

Patients with non-alcoholic liver disease-Sixteen patients with various non-alcoholic related liver diseases (including autoimmune liver disease, acute and chronic hepatitis, and cryptogenic cirrhosis) were studied, of whom four were cirrhotic. None admitted to drinking over $20 \mathrm{~g}$ alcohol daily.

Controls-Fourteen patients undergoing investigation for dyspepsia served as controls. All had normal standard liver function values and were drinking under $20 \mathrm{~g}$ alcohol daily.

Table I shows the age and sex distribution, mean red cell corpuscular volume, and routine liver function test results in each group.

Routine liver function tests were performed by a standard automated method, and mean corpuscular volume was measured with a Coulter counter. Thiamine, thiamine monophosphate, and thiamine pyrophosphate were assayed by the thiochrome method. ${ }^{8}$ Fasting whole blood samples collected into lithium-heparin tubes were treated with perchloric acid, and the soluble fraction was run through ion exchange columns (analytical grade 1 bicarbonate plus Amberlite CG50) to separate thiamine and its phosphate esters. Thiamine (unphosphorylated) was assayed direct by the thiochrome method, while the thiamine ester fractions were treated with phosphatase to degrade them to thiamine before they were assayed, also by the thiochrome method. Recoveries of total thiamine after ion exchange chromatography were between $95 \%$ and $104 \%$.

The reaction of thiamine with alkaline potassium ferricyanide resulting in the formation of thiochrome is specific for thiamine. The interference of other blood borne compounds in this assay by fluorescence was removed by subsequent extraction of thiochrome into isobutanol. When necessary all measurements were corrected for sample blanks obtained by omitting potassium ferricyanide in the reagent.

\section{Results}

\section{NUTRITIONAL STATE}

As judged by anthropometric criteria (triceps skinfold thickness, mid-arm circumference, mid-arm muscle circumference) the three groups were of similar overall nutritional state (table I).

\section{BLOOD THIAMINE}

There were no significant differences among the groups in respect of the mean values of any of the thiamine fractions measured. Table II gives the mean results for thiamine, thiamine monophosphate, thiamine pyrophosphate, and total thiamine, which was calculated from the sum of the three fractions; figure 2 shows the individual values. There was a considerable difference among the groups, however, in the scatter of results, reflected in the standard deviations. Three alcoholics $(13 \%)$ had low concentrations of total thiamine ( $>2$ SD below the mean of the control group), and two of these patients also had low values of the coenzyme thiamine pyrophosphate.

TABLE II-Blood thiamine concentrations (nmol/l) in patients studied. Values are means ( $S D$ in parentheses)

\begin{tabular}{lcccc}
\hline & Thiamine & $\begin{array}{c}\text { Thiamine } \\
\text { monophosphate }\end{array}$ & $\begin{array}{c}\text { Thiamine } \\
\text { pyrophosphate }\end{array}$ & $\begin{array}{c}\text { Total } \\
\text { thiamine }\end{array}$ \\
\hline $\begin{array}{l}\text { Alcoholic liver } \\
\text { disease }\end{array}$ & $10.3(15 \cdot 0)$ & $69.9(24)$ & $49.4(16)$ & $130(46)$ \\
$\begin{array}{l}\text { Non-alcoholic liver } \\
\text { disease }\end{array}$ & $\begin{array}{l}6.0(4.0) \\
\text { Controls }\end{array}$ & $\begin{array}{l}74 \cdot 8(1.7) \\
70.4(10)\end{array}$ & $\begin{array}{l}44 \cdot 2(16) \\
46.4(12)\end{array}$ & $126(25)$ \\
\hline
\end{tabular}

Conversion: SI to traditional units-Thiamine: $1 \mathrm{nmol} / 1 \approx 265 \cdot 4 \mathrm{ng}$ thiamine base $/ 1$. (Thiamine monophosphate and thiamine pyrophosphate degraded to thiamine before assay.)

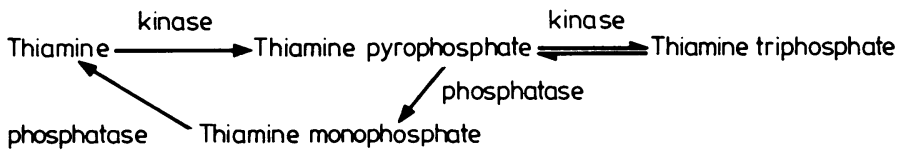

FIG 1-Metabolic relation of phosphate esters of thiamine.

Surprisingly, four alcoholics $(17 \cdot 4 \%)$-all with established cirrhosis -had abnormally high blood concentrations of total thiamine, and three of these also had high values of the active coenzyme. Seven of the 23 alcoholics had high thiamine concentrations, the values being up to 10 times the mean of the control group. The two patients with the highest concentrations of thiamine were both cirrhotic alcoholics and were the most severely ill of the group. One died of hepatorenal failure; the other had superimposed alcoholic hepatitis and subsequently developed ascites.

Less pronounced differences were seen between patients with non-alcoholic liver disease and the controls. Two of the 16 patients had a slightly raised total thiamine concentration, and in one of these the pyrophosphate fraction was also increased. Three patients with non-alcoholic liver disease had moderately raised unphosphorylated thiamine concentrations (fig 2).

TABLE I-Clinical and laboratory details of patients studied. Values are means (SD in parentheses)

\begin{tabular}{|c|c|c|c|c|c|c|c|c|c|}
\hline & $\begin{array}{c}\text { No of } \\
\text { patients }\end{array}$ & $\underset{\text { (years) }}{\text { Age }}$ & Men:women & $\begin{array}{c}\text { Alkaline } \\
\text { phosphatase } \\
\text { activity } \\
(\mathrm{IU} / 1)\end{array}$ & $\begin{array}{l}\text { Alanine } \\
\text { transferase } \\
\text { activity } \\
\text { (IU/1) }\end{array}$ & $\begin{array}{c}\text { Mean } \\
\text { corpuscular } \\
\text { volume } \\
(\mathrm{f})\end{array}$ & $\begin{array}{c}\text { Triceps } \\
\text { skinfold } \\
\text { thickness } \\
(\mathrm{mm})\end{array}$ & $\begin{array}{l}\text { Mid-arm } \\
\text { circumference } \\
(\mathrm{cm})\end{array}$ & 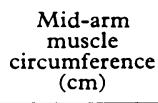 \\
\hline $\begin{array}{l}\text { Alcoholic liver disease } \\
\text { Non-alcoholic liver disease } \\
\text { Controls }\end{array}$ & $\begin{array}{l}23 \\
16 \\
14\end{array}$ & $\begin{array}{l}48(14) \\
49(19) \\
47(12)\end{array}$ & $\begin{aligned} 15: 8 \\
8: 8 \\
9: 5\end{aligned}$ & $\begin{array}{r}120(90) \\
252(306) \\
50(22)\end{array}$ & $\begin{array}{r}57(46) \\
209(358) \\
25(23)\end{array}$ & $\begin{array}{r}100(7 \cdot 0) \\
90(4 \cdot 4) \\
88(6 \cdot 0)\end{array}$ & $\begin{array}{l}11 \cdot 2(5 \cdot 6) \\
12 \cdot 4(7 \cdot 9) \\
12 \cdot 1(4 \cdot 2)\end{array}$ & $\begin{array}{l}27 \cdot 4(4) \\
26 \cdot 2(3) \\
28 \cdot 7(3)\end{array}$ & $\begin{array}{l}23 \cdot 9(3 \cdot 5) \\
22 \cdot 3(2 \cdot 2) \\
25 \cdot 1(3 \cdot 7)\end{array}$ \\
\hline
\end{tabular}



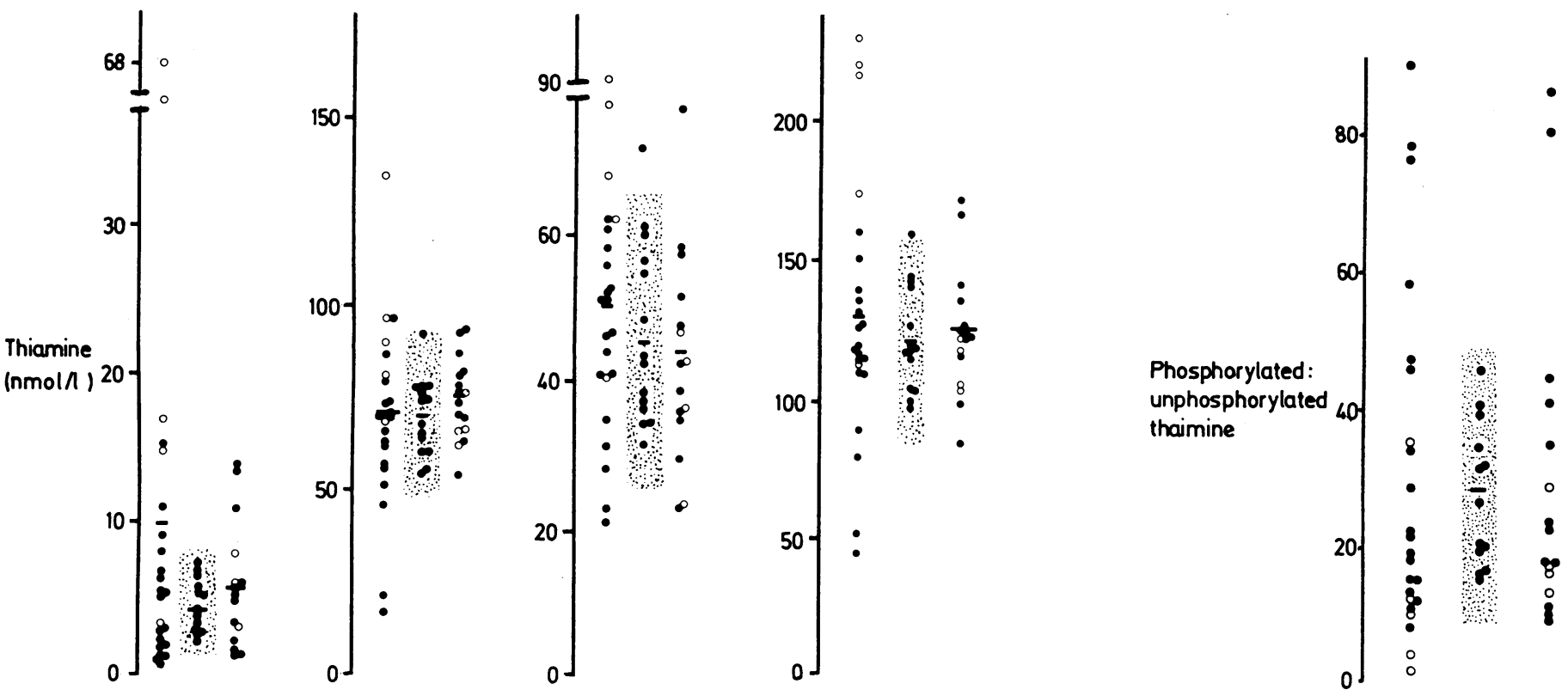

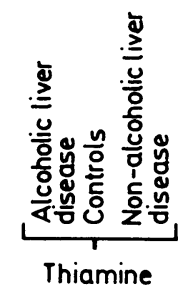

Fig. 2

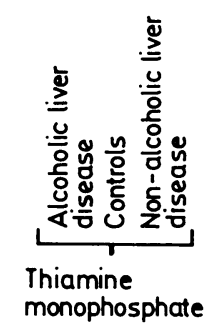

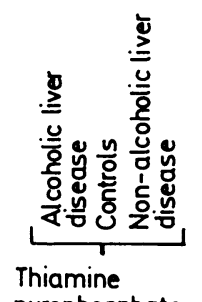

pyrophosphate

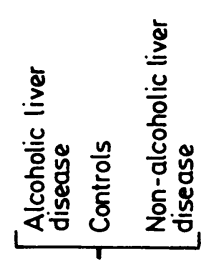

Total thiamine

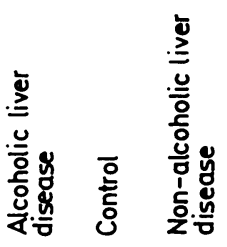

FIG 2-Individual values of thiamine fractions and total thiamine in the three groups of patients. Bars and stippled areas denote mean value and 2 $\mathrm{SD}$ of control mean. ( $\mathrm{O}=$ Patients with cirrhosis.)

Conversion: SI to traditional units-Thiamine: $1 \mathrm{nmol} / 1 \approx 265.4 \mathrm{ng}$ thiamine base/1. (Thiamine monophosphate and thiamine pyrophosphate degraded to thiamine before assay.)

FIG 3-Individual ratios of phosphorylated to unphosphorylated thiamine-(thiamine monophosphate + thiamine pyrophosphate)/thiamine-in the three groups of patients. Bar and stippled area denote mean and $2 \mathrm{SD}$ of control mean. $(\mathrm{O}=$ Patients with cirrhosis.)

\section{THIAMINE PHOSPHORYLATION}

In an attempt to determine whether liver disease was associated with a defect in thiamine phosphorylation the ratio of phosphorylated to unphosphorylated thiamine-(thiamine monophosphate + thiamine pyrophosphate)/thiamine-was calculated for each group of patients (fig 3). Any defect in phosphorylation should be manifested by a low ratio. This was observed in two patients with alcoholic liver disease but in none of the patients with other types of liver disease. The two patients with a low ratio, however, were the severely ill alcoholics described above, both of whom had normal thiamine pyrophosphate values.

\section{Discussion}

The major difficulty in interpreting other studies of thiamine state in alcoholics is that they have used indirect assays or techniques that cannot distinguish between total thiamine and the pyrophosphate coenzyme. Although measurement of the activity of the thiamine pyrophosphate dependent enzyme transketolase has been most widely used, the indirect nature of this assay and its lack of correlation with other methods of assessing thiamine state $^{45}$ make its suitability questionable. Measurement of the thiamine pyrophosphate effect (the increase in activity of transketolase after the addition of excess thiamine pyrophosphate in vitro) goes some way to meeting these objections. Nevertheless, this assay makes certain assumptions about the relation between thiamine and transketolase activity that may not be valid, particularly in alcoholics. ${ }^{910} \mathrm{We}$ have resolved these problems by using an analytical technique that allows the separation and individual assay of free thiamine and its major phosphate esters.

In other studies thiamine deficiency was most frequently found in skid row alcoholics, up to $80 \%$ of whom had biochemical evidence of vitamin deficiency. ${ }^{3}$ Even in well nourished alcoholics as many as $30 \%$ have been reported to have subclinical thiamine deficiency as judged by reduced activity of transketolase. ${ }^{11}$ In a recent report only a small proportion of patients with low transketolase activity were found to have an increased thiamine pyrophosphate effect. ${ }^{11}$ In another study alcoholic patients with low transketolase activity not increased by the addition of thiamine pyrophosphate were reported to recover normal transketolase activity after receiving parenteral thiamine for a week. ${ }^{12}$ The findings were interpreted as evidence that thiamine deficiency causes a reduction in synthesis or activity of the transketolase apoenzyme. We, however, do not know of any evidence that transketolase synthesis is regulated by the availability of thiamine, and it may be relevant that in animal studies ethanol and acetaldehyde inhibit transketolase activity.

In our study biochemical thiamine deficiency (defined as a blood concentration of the coenzyme thiamine pyrophosphate $>2 \mathrm{SD}$ below the mean of the controls) was found in under $9 \%$ of patients with alcoholic liver disease, a figure more in keeping with other reports on the prevalence of an increased effect of the coenzyme than of impaired transketolase activity in comparable groups of well nourished alcoholics. ${ }^{11}$

A new finding from our study was the surprising number of alcoholics-particularly those with cirrhosis-who had abnormally high blood thiamine values. A dietary source (no 
patient had received vitamins before the study) or endogenous bacterial synthesis seems unlikely to account for this. The liver, however, is the principal storage organ for thiamine, and high circulating concentrations might be accounted for by impaired uptake or increased release of stored thiamine by ethanol. There may be an analogy with the finding of high blood concentrations of vitamin $B_{12}$ released from damaged hepatocytes in patients with liver disease. Experiments show that ethanol infusion results in release of thiamine into rat liver perfusates and that in the presence of ethanol thiamine rebinding does not occur. ${ }^{13}$

Decreased phosphorylation of thiamine to the active coenzyme thiamine pyrophosphate has been suggested as one possibly important factor in thiamine deficiency in alcoholics ${ }^{14}$; we, however, found no evidence for this. On the contrary, patients with low concentrations of thiamine pyrophosphate had vanishingly low values of unphosphorylated thiamine and a high ratio of phosphorylated to unphosphorylated thiamine, suggesting that the phosphorylating mechanism was functioning efficiently. The few patients in whom an abnormal ratio suggested the possibility of a phosphorylation defect had normal or high concentrations of thiamine pyrophosphate. This should be investigated further in kinetic studies of thiamine phosphorylation in vivo. Nevertheless, our present findings using a direct assay of thiamine and its important metabolites indicate that some conclusions about the prevalence and mechanism of thiamine deficiency in alcoholics drawn from studies using indirect methods may not be valid.
MKG is a member of the external scientific staff of the Medical Research Council.

\section{References}

' Neville JM, Eagle JA, Samson G, Olson RE. Nutritional status of alcoholics Am F Clin Nutr 1968;21:1329-40.

Gaitonde MK. Critique: neurotransmitter function in thiamine deficiency and encephalopathy. Neurochemistry International 1982;4:465-6.

- Leevy CM, Cardi L, Frank O, Gellene R, Baker H. Incidence and significance of hypovitaminemia in a randomly selected municpal hospital population. Am f Clin Nutr 1965;17:259-71.

- McLaren DS, Docherty MA, Boyd DHA. Plasma thiamine pyrophosphate and erythrocyte transketolase in chronic alcoholism. Am $\mathcal{f}$ Clin Nutr $1981 ; 34$ $1031-3$.

Warnock LG, Prudhomme CR, Wagner C. The determination of thiamine pyrophosphate in blood and other tissues, and its correlation with erythrocyte transketolase activity. $\mathcal{F}$ Nutr 1978;108:421-7.

Abe T, Itokawa Y. Effect of ethanol administration on thiamine metabolism and transketolase activity in rats. Int $\mathcal{F}$ Vitam Nutr Res 1977;47:307-14.

Kirk JR. Automated method for the analysis of thiamine in milk, with application to other selected food. I Assoc Off Anal Chem 1974;57:1081-4.

Somogyi JC. Early signs of thiamine deficiency. $\mathcal{F}$ Nutr Sci Vitaminol (Tokyo) $1976 ; 22$ (suppl):29-32.

alterations in thiamine deficiency-their interpretation. Am $\mathcal{f}$ Clin Nutr 1967;20:528-42.

amilo ME Morgan MY, Sherlock S. Erythrocyte transketolase activity in alcoholic liver disease. Scand $\mathcal{F}$ Gastroenterol $1981 ; 16 \cdot 273-9$.

${ }^{12}$ Rossouw JE, Labadarios D, Krasner N, David M, Williams R. Red blood cell transketolase activity and the effect of thiamine supplementation in patients with chronic liver disease. Scand $\mathcal{F}$ Gastroenterol 1978;13:133-8.

${ }^{13}$ Sorrell MF, Baker H, Barak AJ, Frank O. Release by ethanol of vitamins into rat liver perfusates. Am $\mathcal{f}$ Clin Nutr 1974;27:743-5.

"Hoyumpa AM. Mechanisms of thiamine deficiency in chronic alcoholism. Am $\mathfrak{f}$ Clin Nutr 1980;33:2750-61.

(Accepted 24 April 1984)

\section{Augmentin (amoxycillin-clavulanic acid) compared with co-trimoxazole in urinary tract infections}

Many antibiotics are effective in urinary tract infection with sensitive organisms but have seldom been compared for the time taken to achieve clinical cure. This study compares the efficacy of Augmentin (a formulation of amoxycillin with the $\beta$-lactamase inhibitor potassium clavulanate) with that of co-trimoxazole on the basis of time for resolution of symptoms and signs of infection.

\section{Patients, methods, and results}

Inpatients were included in the study only if they had at least two of: (a) fever, (b) urinary tract symptoms, (c) significant numbers of pathogenic organisms in a midstream or catheter urine specimen. Five patients (two in the Augmentin group and three in the co-trimoxazole groud) were admitted to hospital for urinary tract infection. The remainder were admitted for other medical and surgical conditions and had acquired their infections in hospital. Only one patient had an indwelling catheter. The most common pathogens were Escherichia coli or other coliforms. Other organisms included Klebsiella, Proteus, and Streptococcus faecalis.

The study was a single blind comparison, with patients allocated at random to seven days' treatment with either Augmentin $(250 \mathrm{mg}$ amoxycillin +125 mg potassium clavulanate) three times daily or co-trimoxazole $(160 \mathrm{mg}$ trimethoprim $+800 \mathrm{mg}$ sulphamethoxazole) twice daily. Clinical cure was defined as complete resolution of all the presenting symptoms and signs of urinary tract infection. Consecutive patients allocated to each treatment were paired for sequential analysis by the method of Matts ${ }^{1}$ using an RST plan $^{2}$ with $\theta=0.75,1-\beta=0.95$, and $2 \alpha=0.05$, treatment preferences being based on day of clinical cure. The sequential plot reached a boundary indicating a preference for Augmentin after 52 assessable patients (26 receiving each treatment) had been entered. There were no significant differences between the two groups on entry in age, sex, primary illnesses, and symptoms and signs of urinary tract infection. All patients had a bacterial culture of $>10^{8}$ organisms/l urine and all completed the study.

All 26 patients in the Augmentin group were cleared of the causative organism compared with 23 of the 26 patients $(88 \%)$ in the co-trimoxazole group $\left(\chi^{2}: p=0 \cdot 08\right)$. There was a good correlation between the clinical and bacteriological results (table).

All patients in the Augmentin group had infections sensitive to Augmentin and $25(96 \%)$ were clinically cured; in the co-trimoxazole group only 21 patients $(81 \%)$ had infections sensitive to co-trimoxazole, of which 20 were clinically cured $(95 \%)$. Of those patients cured, however, the mean time to clinical cure was 3.2 days (range 2-5) in the Augmentin group compared with $4 \cdot 7$ days (range 1-7) in the co-trimoxazole group, and this difference was significant ( $\mathrm{p}=0.0004$; unpaired $t$ test).

Both treatments were well tolerated. No patient withdrew from the study because of an adverse reaction. Two patients in each group had nausea of short duration. One patient taking co-trimoxazole had abdominal pain.

\section{Comment}

The shorter time to clinical cure for patients with sensitive organisms treated with Augmentin compared with that for those with sensitive

\begin{tabular}{|c|c|c|c|c|c|c|c|}
\hline & \multicolumn{4}{|c|}{ Augmentin group } & \multicolumn{3}{|c|}{ Co-trimoxazole group } \\
\hline & $\begin{array}{c}\text { Augmentir } \\
\text { sensitive }\end{array}$ & $\begin{array}{c}\text { Ampicillin } \\
\text { sensitive }\end{array}$ & $\underset{\text { resistant }}{\text { Ampicillin }}$ & $\begin{array}{c}\text { All } \\
\text { patients }\end{array}$ & $\begin{array}{l}\text { Co-trimoxazole } \\
\text { sensitive }\end{array}$ & $\begin{array}{c}\text { Co-trimoxazole } \\
\text { resistant }\end{array}$ & $\begin{array}{c}\text { All } \\
\text { patients }\end{array}$ \\
\hline $\begin{array}{l}\text { Clinical cure (No) } \\
\text { Mean days to cure (SD)* } \\
\text { Bacteriological cure (No) } \\
\text { Total No of patients }\end{array}$ & $\begin{array}{l}25 \\
3 \cdot 2(0 \cdot 9) \\
26 \\
26\end{array}$ & $\begin{array}{c}18 \\
3 \cdot 1(0.9) \\
18 \\
18\end{array}$ & $\begin{array}{c}7 \\
3 \cdot 7(0 \cdot 8) \\
8 \\
8\end{array}$ & $\begin{array}{c}25 \\
3 \cdot 2(0 \cdot 9) \\
26 \\
26\end{array}$ & $\begin{array}{l}20 \\
4 \cdot 7(1 \cdot 6) \\
21 \\
21\end{array}$ & $\begin{array}{c}2 \\
5 \cdot 5(3 \cdot 5) \\
2 \\
5\end{array}$ & $\begin{array}{l}422 \\
4 \cdot 8(1 \cdot 7) \\
23 \\
26\end{array}$ \\
\hline
\end{tabular}

*Of those cured. 